\title{
Effects of local departures from nominal dimensions on stresses in thin torispherical end closures
}

DOI:

10.1243/03093247V314315

\section{Document Version}

Accepted author manuscript

Link to publication record in Manchester Research Explorer

\section{Citation for published version (APA):}

Tafreshi, A., \& Thorpe, T. E. (1996). Effects of local departures from nominal dimensions on stresses in thin torispherical end closures. Journal of Strain Analysis For Engineering Design, 31(4), 315-324.

https://doi.org/10.1243/03093247V314315

\section{Published in:}

Journal of Strain Analysis For Engineering Design

\section{Citing this paper}

Please note that where the full-text provided on Manchester Research Explorer is the Author Accepted Manuscript or Proof version this may differ from the final Published version. If citing, it is advised that you check and use the publisher's definitive version.

\section{General rights}

Copyright and moral rights for the publications made accessible in the Research Explorer are retained by the authors and/or other copyright owners and it is a condition of accessing publications that users recognise and abide by the legal requirements associated with these rights.

\section{Takedown policy}

If you believe that this document breaches copyright please refer to the University of Manchester's Takedown Procedures [http://man.ac.uk/04Y6Bo] or contact uml.scholarlycommunications@manchester.ac.uk providing relevant details, so we can investigate your claim.

\section{OPEN ACCESS}


Tafreshi, A. \& Thorpe, T. E. Jul 1996 In : Journal of Strain Analysis for Engineering Design. 31, 4, p. 315-324 10 p.

\title{
EFFECTS OF LOCAL DEPARTURES FROM NOMINAL DIMENSIONS ON
}

STRESSES IN THIN TORISPHERICAL END-CLOSURES

\author{
A. TAFRESHI \\ Division of Mechanical and Nuclear Engineering \\ The Manchester School of Engineering \\ University of Manchester \\ T. E. THORPE \\ Division of Mechanical and Nuclear Engineering \\ The Manchester School of Engineering \\ University of Manchester
}

A detailed survey (1-4) of the variations in crown curvature, knuckle curvature and thickness of a number of thin torispherical pressure ends has shown that actual dimensions may differ significantly from nominal dimensions.

Numerical stress analysis using the finite element method has been carried out to assess the effects of these shape imperfections on the stresses in some of the thin torispherical pressure vessel ends considered in (4). The results have been compared with those for the corresponding perfect ends. In several cases significant increases in stress levels are predicted due to thickness and especially curvature variations.

\section{INTRODUCTION}

A detailed shape/thickness survey of a series of very thin stainless steel pressure vessel ends 
was carried out by Campbell \& Stanley (1-4). These were full-size torispherical ends manufactured from an austenitic stainless steel, using either the 'Crown and Segment' or 'Pressed and Spun' constructions. A 'Pressed and Spun' end is formed from a single flat circular sheet while a 'Crown and Segment' end is fabricated from a number of pre-formed panels. This survey showed some significant departures in the dimensions of the actual torispherical end closures from their nominal design values. Consequently, it can be anticipated that stress levels in the vessels, when subjected to internal pressure, will also differ from intended values.

This paper describes work, using finite element analysis, to establish the extent of the departure of stress levels from those in corresponding geometrically perfect ends, in typical imperfect thin walled torispherical end closures covered by Stanley \& Campbell (4). Only imperfections in the meridional plane have been considered in this paper, so that the models analysed are assumed to be axi-symmetric.

\section{NOTATION}

\section{(See Fig.1)}

h Height of End

I Knuckle radius

t Thickness

D Cylinder diameter

E Young's Modulus

I Stress index (Normalized to nominal stress $\mathrm{pD}_{\mathrm{i}} / 2 \mathrm{t}_{\mathrm{c}}$ ) 
L Length of cylinder

p Internal pressure

$\mathrm{R} \quad$ Crown radius

S Meridional distance from the pole.

z Axial coordinate

$\alpha \quad$ Angle subtended by knuckle arc at centre of meridional curvature

$v \quad$ Poisson's ratio

\section{Subscripts}

c Circumferential, cylinder

e End

i Inner

m Meridional

o Outer

3. STRESS ANALYSIS USING THE FINITE ELEMENT METHOD

\subsection{Models Analyzed}

Fig. 1 shows a cylindrical pressure vessel with typical torispherical end closures. The end comprises a portion of a toroid (the knuckle), capped by a spherical segment (the crown). There is no discontinuity in slope at either the drum-knuckle junction or the knuckle-crown junction. The end dimensions ( $t, r, R, h$ ) can be expressed by a set of non-dimensional 
parameters $(t / D, r / D, R / D, h / D)$ together with the knuckle angle $(\alpha)$. Geometrically an end is completely defined by the thickness parameter (t/D) and any other two of the above parameters.

Table 1 shows the dimensions of the end models; these are the spun ends described by Stanley \& Campbell (4). The model series covers a practically useful range of knuckle radius $\left(0.056 \leq r_{i} / D_{i} \leq 0.111\right)$, crown radius $\left(0.722 \leq R_{i} / D_{i} \leq 1.0\right)$ and knuckle angle $\left(48^{\circ} \leq \alpha \leq 64^{\circ}\right)$. To aid comparisons, the end numbers in Table 1 correspond to those of Stanley \& Campbell (4)

\subsection{Mesh Generation, Element Type and Boundary Conditions}

IDEAS (5) is a commercial CAD/CAE package which was used for pre- and post-processing of the finite element mesh and display of the results. IDEAS was then interfaced with the general purpose finite element software ABAQUS(6) to calculate stresses.

Axi-symmetric double ended models of the pressure vessels were considered and because of the double symmetry only one quarter of each model was analysed. Loading was due to internal pressure. Three-noded parabolic axi-symmetric shell elements (designated SAX2 in (6)) were used for finite element mesh discretization. While these are shell elements, they are also simple extensions of the beam elements. The extension is the addition of the circumferential stress components to the already existing meridional components. They are thus one-dimensional (5), deforming in a meridional plane. The cartesian coordinates in this plane are $\mathbf{r}$ (radial) and $\mathrm{z}$ (axial position); degrees of freedom are radial and axial 
displacements and rotation in $\mathrm{r}-\mathrm{z}$ plane. This type of element uses two-point integration for the stiffness and three -point integration for the load distribution of a quadratic interpolation function. SAX2 use a consistent mass matrix.

In the models analysed the geometric nonlinearity was ignored and the analysis assumed linear elastic behaviour with small displacements. However for verification purposes ends No. 3 and 8 were analysed assuming linear elastic behaviour with large displacements (i.e. with nonlinear geometry). The differences between the stress results were negligible. This contrasts with buckling analysis where it has been shown (7) that the nonlinear nature of the geometry can not be ignored.

For boundary conditions, the pole (point A in Fig. 1) was fixed in the radial direction (r), while point B, "remote" from the drum-knuckle junction, was fixed in the axial direction. Both points were restrained against rotation in the $\mathrm{r}-\mathrm{z}$ plane. Fig. 2 shows part of a typical perfect torispherical end (curve a), together with the exaggerated deformed profile, due to internal pressure, obtained from the analysis. It can be seen that the knuckle displaces inwards and the crown area has the maximum displacement.

The ABAQUS package allows shell thicknesses to be specified at the nodes. This option simplifies the definition of non-constant shell thicknesses such as those found in composites, injection molded components and pressure vessels. For the variable thickness analysis, the shell thickness is interpolated from the specified nodal thickness values. For elements with more than one integration point, this approach results in a thickness which can vary over the element. For the analysis the mean dimensions of the end and cylinder were considered 
throughout because the elements lie on the shell middle surface.

The computational analyses were carried out on HP835 and Cray EL98 computers.

\section{RESULTS}

A series of FE analyses has been conducted on eleven different torispherical ends (Table 1) both before and after the introduction of different forms of shape imperfections. These shape imperfections are curvature and thickness variations in the end which in some cases differ significantly from nominal dimensions. In order to assess the importance of these shape imperfections on the stresses developed in the torispherical ends, the real vessels with curvature and thickness variations were modelled, analysed and then the results compared with corresponding perfect ends.

The finite element analysis results were examined in terms of stress indices for inner and outer surface circumferential and meridional stresses. These were normalized to nominal circumferential stress in the cylinder.

\subsection{Torispherical pressure vessels with perfect ends}

To judge the effects of curvature and thickness variations in pressure vessels, it was first necessary to determine stresses in perfect end closures. The nominal dimensions of the ends 
studied are given in Table 1. Columns 2 to 5 of Table 2 show the stress indices for these ends with perfect geometries for the knuckle and crown.

It can be seen that the compressive outer surface circumferential stress index $I_{o c}$ is the greatest stress in the end in all cases. Generally, for constant values of cylinder diameter and crown radius, the stress index increases as the knuckle radius decreases. End no.12, with the smallest value of $\mathrm{r} / \mathrm{D}$, has the maximum stress index. For constant values of cylinder diameter and knuckle radius, increasing crown radius is associated with increasing stress index. However, in the cases studied, the maximum stresses, as opposed to stress indices, occur in the vessels with greatest cylinder diameter.

The distribution of circumferential and meridional stress indices on the inner and outer surfaces of end 3 are shown in Fig.3. Stress index values are plotted against the zcoordinate in the end, knuckle and cylinder. The stresses in the end near to the pole and also along the cylinder far from the knuckle-cylinder junction are uniform but elsewhere are highly nonilinear with respect to $\mathrm{z}$, especially in the knuckle region. The inner and outer surface meridional stresses are almost equal in magnitude but opposite in sign indicating a predominance of bending. Circumferential stresses on the inner and outer surfaces are almost equal both in magnitude and sign, as is typical of membrane stresses. These circumferential stresses are tensile in the crown and cylinder, but compressive in the knuckle region(7). The maximum stress is the circumferential compression on the outer surface of the knuckle. This confirms results obtained by other investigators (8) and is an important reason for buckling of thin torispherical end pressure vessels in the knuckle region. This feature contrasts with the stress distribution in torispherical pressure vessels with thick ends in which the maximum 
stress is the tensile meridional stress on the inner surface of the knuckle.

The outer surface meridional stress has a peak tensile value in the end, close to the crownknuckle junction, and then decreases sharply into the knuckle. Except the inner surface meridional stress which is highly tensile, the stresses on the crown side of the knuckle area are highly compressive

\subsection{Torispherical pressure vessels with shape \& thickness imperfections}

Measured values, from (2), of thicknesses and curvatures along meridians of ends No. 3 , 4 and 5 are shown in Figs. 4 and 5, and for ends No. 8, 10 and 16 in Figs. 6 and 7.

In each case the nominal crown thickness is $0.128 \mathrm{in}(3.2512 \mathrm{~mm})$. For end 3 the crown thickness is reasonably uniform at approximately $0.132 \mathrm{in}(3.3528 \mathrm{~mm})$, but there is a thickness reduction of the order of $0.02 \mathrm{in}(0.508 \mathrm{~mm})$ in the knuckle. Irregularities in the knuckle thickness in this end can be observed with a thickness decrease of approximately $0.02 \overline{5}^{\text {in }}(0.635 \mathrm{~mm})$ in at the knuckle-cylinder junction. For ends 4 and 5 the thickness decreases from the crown-knuckle junction to the knuckle-cylinder junction. Typically the thickness reduction at the centre of the knuckle is of the order of $0.02-0.025$ in(0.508-0.635 $\mathrm{mm}$ ). For end no 5 the minimum measured thickness at the knuckle-cylinder junction is $0.093 \mathrm{in}(2.3622 \mathrm{~mm})$, about $0.015 \mathrm{in}(0.381 \mathrm{~mm})$ less than the cylinder thickness.

In end 3 the curvature of the crown varies from 0.008 to 0.028 in $^{-1}(0.000314$ to 0.001102 $\left.\mathrm{mm}^{-1}\right)$, the nominal value being $0.018 \mathrm{in}^{-1}\left(0.000708 \mathrm{~mm}^{-1}\right)$. Thereafter the curvature decreases to a negative value just before the crown-knuckle junction before increasing steeply 
at the junction. In ends 4 and 5 the curvature variations are of same general form as those in end 3 but tend to be greater. Ends 4 and 5 show significant negative curvatures in the crown just before the crown-knuckle junction. The measured curvatures are within $\pm 13 \%$ of the nominal value, with the maximum departure at the crown-knuckle junction.

A FORTRAN computer program was developed to read in the curvatures at a series of points on the end and calculate their coordinates assuming there is a circular arc of the given curvature between any two adjacent points. For the best accuracy the chosen points were closely spaced. To maximize smoothness and prevent shape oscillation, spline fitting was used through the points (see (9) \& (10)). To verify this method, a series of points was chosen on a perfect end and then a spline was fitted through the points to model the end. The shape produced matched the perfect end constructed from two circular arcs, and subsequent FE analysis showed that the stress values were identical in both ends

Fig. 8 shows to scale the shape of end 3 with the curvature imperfections indicated in Fig. 5 , and also the comparable perfect geometry. This indicates that profile errors which are not immediately apparent, nevertheless result in significant stress differences from design values.

\subsubsection{Thickness variations in ends of perfect profile}

In order to assess the effect of thickness variations in stresses developed in pressure vessel ends, the ends with perfect curvatures but with thickness variations were analysed. Columns 6 to 9 of Table 2 show the stress indices of ends 3,4 and 5 with the thickness variations shown in Fig. 4. For ends 3 and 5 the differences between the results for the perfect end 
with uniform thickness and the end with thickness variations are within the range $-2 \%$ to $+4 \%$ of the value for perfect ends. In end 4 the differences range from $-9 \%$ to $+18 \%$, perhaps because of a sharp decrease of thickness in the knuckle region.

The distribution of circumferential and meridional stress indices on the inner and outer surfaces of end 3 with thickness variations are shown in Fig. 9. In comparison with the perfect end, the trends of the stress distributions are similar. The greatest difference occurs in the cylinder at about $25 \mathrm{~mm}$ from the knuckle/cylinder junction. Here the imperfect end has slightly greater and sharper peaks in the meridional stresses.

\subsubsection{Curvature variations in end of uniform thickness}

In order to assess the effect of curvature variations only, it was assumed the thickness was uniform on the end (nominal value) and stress analysis was carried out on ends $3,4,5,8$, 10 and 16 with the curvature variations shown in Figs. 5 and 7 . Curvature variations in the cylindrical drum were not modelled. Columns 10 to 13 of Table 2 show the stress indices for these ends.

Here the differences between the indices for perfect ends and those with curvature variations is quite considerable. Changes of up to $60 \%\left(\mathrm{I}_{\mathrm{OM}}\right.$ in end no. 4) in the quoted index peaks have been established, although these larger changes occur in the minor peaks. The greatest peak, in the outer surface circumferential stress distribution, increases by a more modest $27 \%\left(\mathrm{I}_{\mathrm{oC}}\right.$ in end no. 4). Due to the random nature of the curvature variations observed, some stress levels are reduced by up to $25 \%$ in comparison to perfect ends.

However, the indications of this study are that discrepancies in curvature have a considerably 
greater effect in stress levels than variations in thickness.

The distribution of circumferential and meridional stress indices on the inner and outer surfaces of end no. 3 with curvature variations only are shown in Fig. 10. In comparison with the perfect end, the trends of the stress distributions are similar, but the peak in the inner surface meridional stress has increased and moved nearer the end.

\subsubsection{Torispherical end with curvature and thickness variations}

Columns 14-17 of Table 2 show the FE results of ends 3, 4, 5, 8, 10 and 16 with the combined curvature and thickness variations shown in Figs.4-7.

As may be anticipated from the foregoing study of separate thickness and curvature variations, the combined effect is dominated by curvature variations with some modification due to thickness changes. In some cases the latter add to the changes due to curvature imperfections while in other cases the stress increases are moderated by the thickness effects. The greatest stresses in the ends considered vary from values for perfect ends by $-23 \%$ to $+28 \%$.

Fig. 11 shows the stress distributions in real end 3 with thickness and curvature variations. Stress distribution trends are similar to the perfect end except in two regions. Firstly, in the crown near the pole there are large fluctuations of stresses which are due to large variations of curvatures in this region, while in the perfect end the distributions are quite uniform. Secondly, in the perfect end the inner and outer surface meridional stresses and also inner and outer surface circumferential stresses, respectively, cross each other on the cylinder- 
knuckle junction while in the end with thickness and curvature variations they cross in the knuckle just before the junction.

\subsubsection{Comparisons of finite element and experimental data}

Columns 18 to 21 of Table 2 show the stress indices of all the spun ends determined by the use of electrical resistance strain gauges on full sized vessels (1). The corresponding FE results are those in columns 14 to 17 . Vessel with end no. 8 shows large differences in the results obtained by the two techniques and warrants further investigation. For the other 5 ends analysed by both techniques, the differences are within $-15 \%$ to $+20 \%$. Two points may be considered in explaining this wide difference. Firstly the ERS gauge technique, being a point by point method, will not always yield the true peak stress value. Secondly, the FE models assume rotational symmetry, whereas the real vessels had circumferential variations of thickness and curvature.

Figs 12 and 13 show the effect of crown radius on the peak stress indices $I_{o c}$ and $I_{i m}$ respectively. They show the FE results for perfect and real ends and also experimental results. As mentioned before, the $F E$ results show that the stress indices increase with increase in crown radius.

\section{CONCLUSIONS}

Finite element models of thin walled cylindrical pressure vessels with torispherical ends have 
been developed in order to assess the effects of thickness and curvature variations on the peak stresses developed. With imperfections found in typical manufacturing procedures, stresses have been shown to differ by a significant amount (up to $60 \%$ ) from those to be expected in perfectly formed vessels. The greatest changes are due to curvature variations, but the effects of thickness variations are also significant.

The large stress differences highlighted in this paper warrant further comprehensive detailed study to establish the value of present design standards.

\section{ACKNOWLEDGEMENTS}

The authors acknowledge the help of Prof P Stanley of the Manchester School of Engineering in bringing the problem considered to their attention, and for his guidance throughout the work.

\section{REFERENCES}

(1) CAMPBELL, T.D., Strains, Deformations and Buckling in Very Thin Torispherical Pressure Vessel Ends, $\mathrm{PhD}$ Thesis, University of Nottingham, 1975

(2) STANLEY, P. and CAMPBELL, T.D., 'Very Thin Torispherical Pressure Vessel Ends : Actual Versus Nominal Dimensions', Int. J. Pressure Vessels and Piping, $1991,46,9-34$

(3) STANLEY, P. and CAMPBELL, T.D., 'Very Thin Torispherical Pressure Vessel Ends under Internal Pressure : Test Procedure and Typical Results', J. Strain 
Tafreshi, A. \& Thorpe, T. E. Jul 1996 In : Journal of Strain Analysis for Engineering Design. 31, 4, p. 315-324 10 p. Analysis 1981, 16, 171-186

(4) STANLEY, P. and CAMPBELL, T.D., 'Very Thin Torispherical Pressure Vessel Ends under Internal Pressure : Strains, Deformations and Buckling Behaviour', $J$. Strain Analysis, $1981,16,187-20$

(5) IDEAS (Integrated Design Engineering Analysis Software), Solid Modelling and Finite Element Modelling Users's Manual, (Structural Dynamics Research Corporation, USA, 1993)

(6) ABAQUS Users's Manual, Version 5.4 (Hibbit, Karlson \& Sorensen Inc., Providence, RI, 1993)

(7) Galletly, G.D. and Moffat, D.G., "Pressure Vessel Design: Concepts and Principles" Edited by J.Spence and A.S. Tooth, 1994, Chapter 7, 245-289

(8) FESSLER, H. and STANLEY, P., 'Stresses in Torispherical Drumheads : A Critical Evaluation', J. of Strain Analysis, 1966, 1, 89-101

(9) TAFRESHI, A and FENNER, R.T. 'Design optimisation using the boundary element method', J. Strain Analysis, 1991, 26, 231-241

(10) TAFRESHI, A. and FENNER, R.T., 'Design sensitivity analysis using the boundary element method', J. Strain Analysis, 1993, 28, 283-291 
Tafreshi, A. \& Thorpe, T. E. Jul 1996 In : Journal of Strain Analysis for Engineering Design. 31, 4, p. 315-324 10 p.

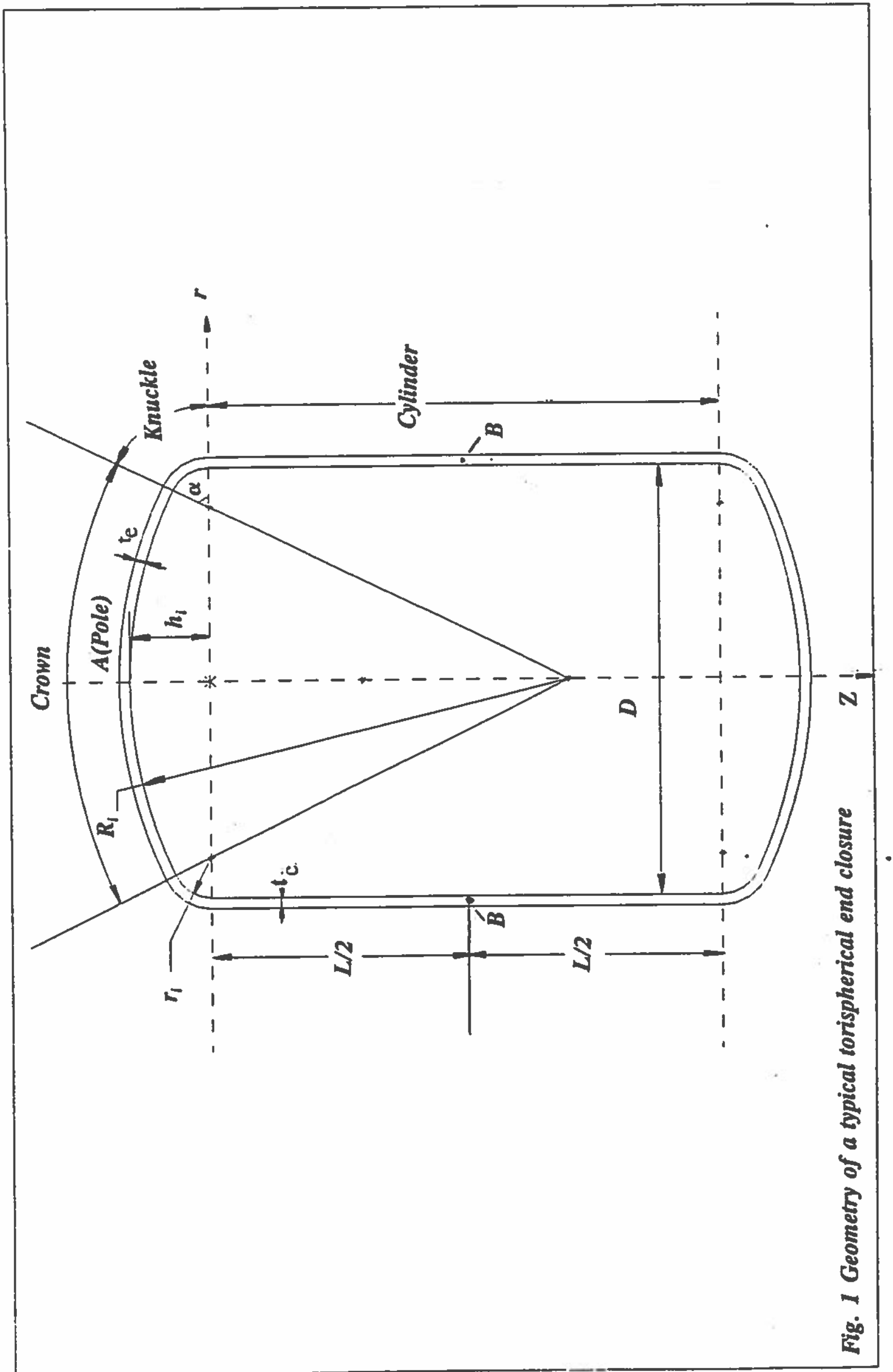


Tafreshi, A. \& Thorpe, T. E. Jul 1996 In : Journal of Strain Analysis for Engineering Design. 31, 4, p. 315-324 10 p.

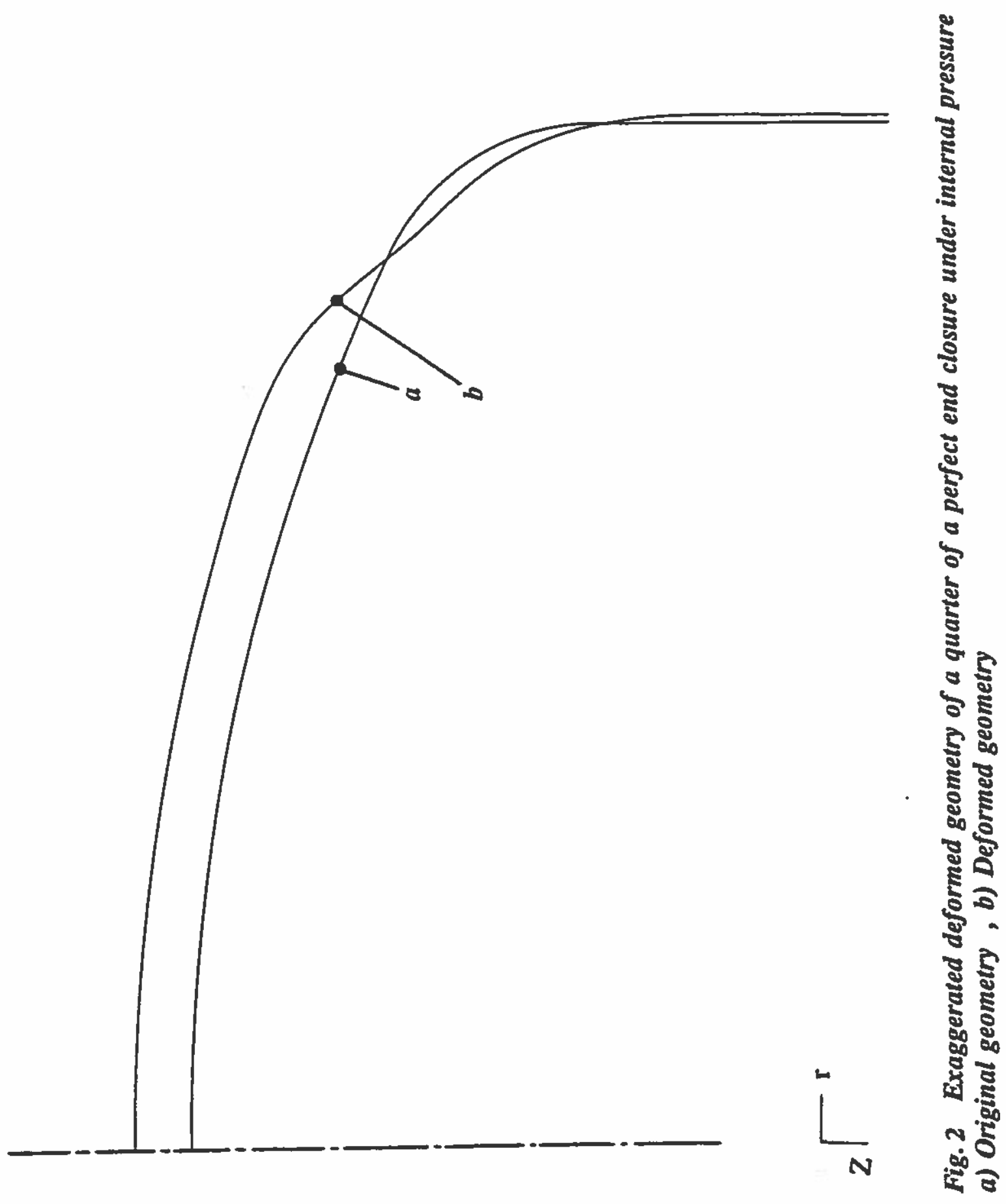


Tafreshi, A. \& Thorpe, T. E. Jul 1996 In : Journal of Strain Analysis for Engineering Design. 31, 4, p. $315-32410$ p.

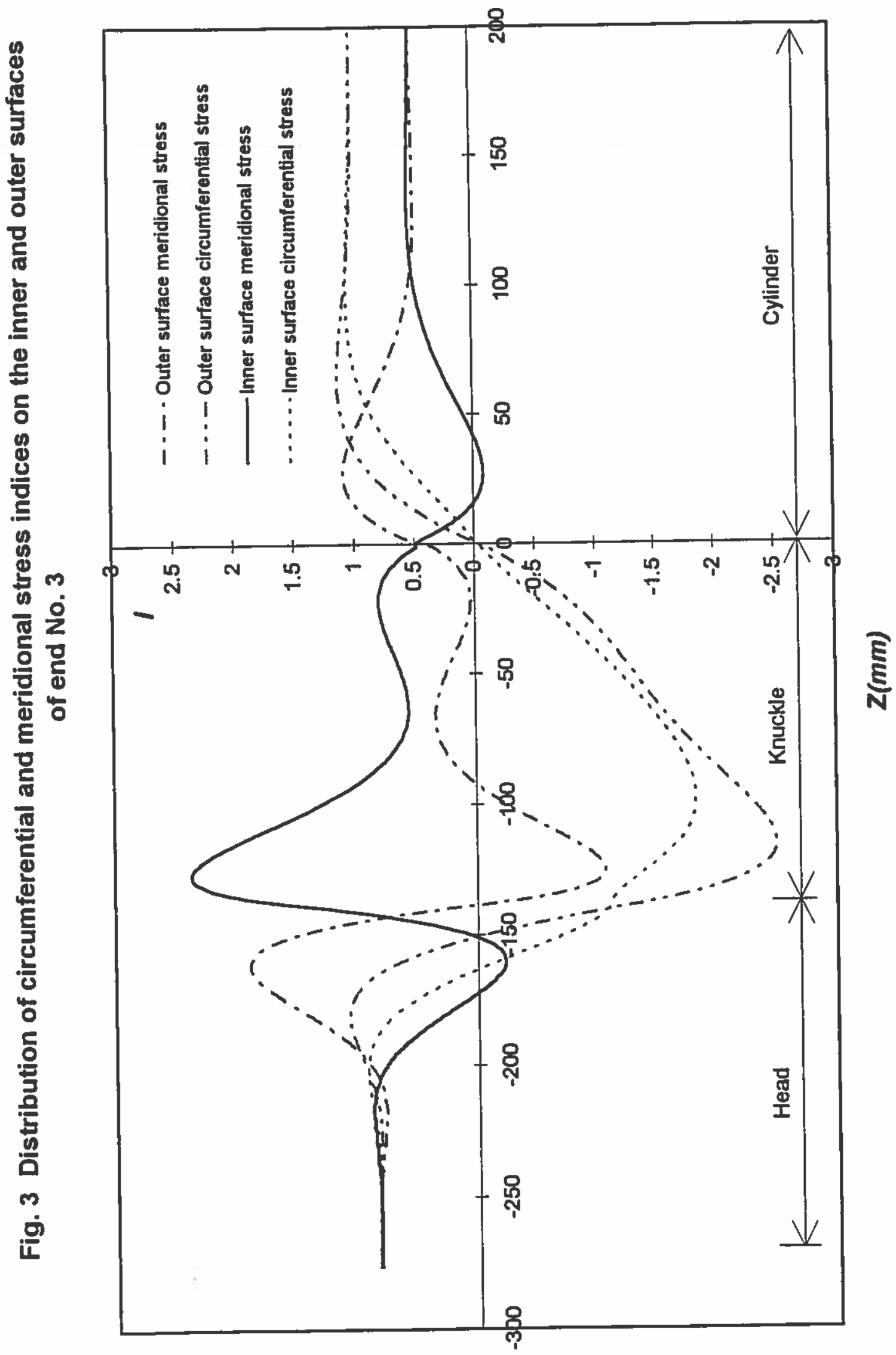


Tafreshi, A. \& Thorpe, T. E. Jul 1996 In : Journal of Strain Analysis for Engineering Design. 31, 4, p. $315-32410$ p.

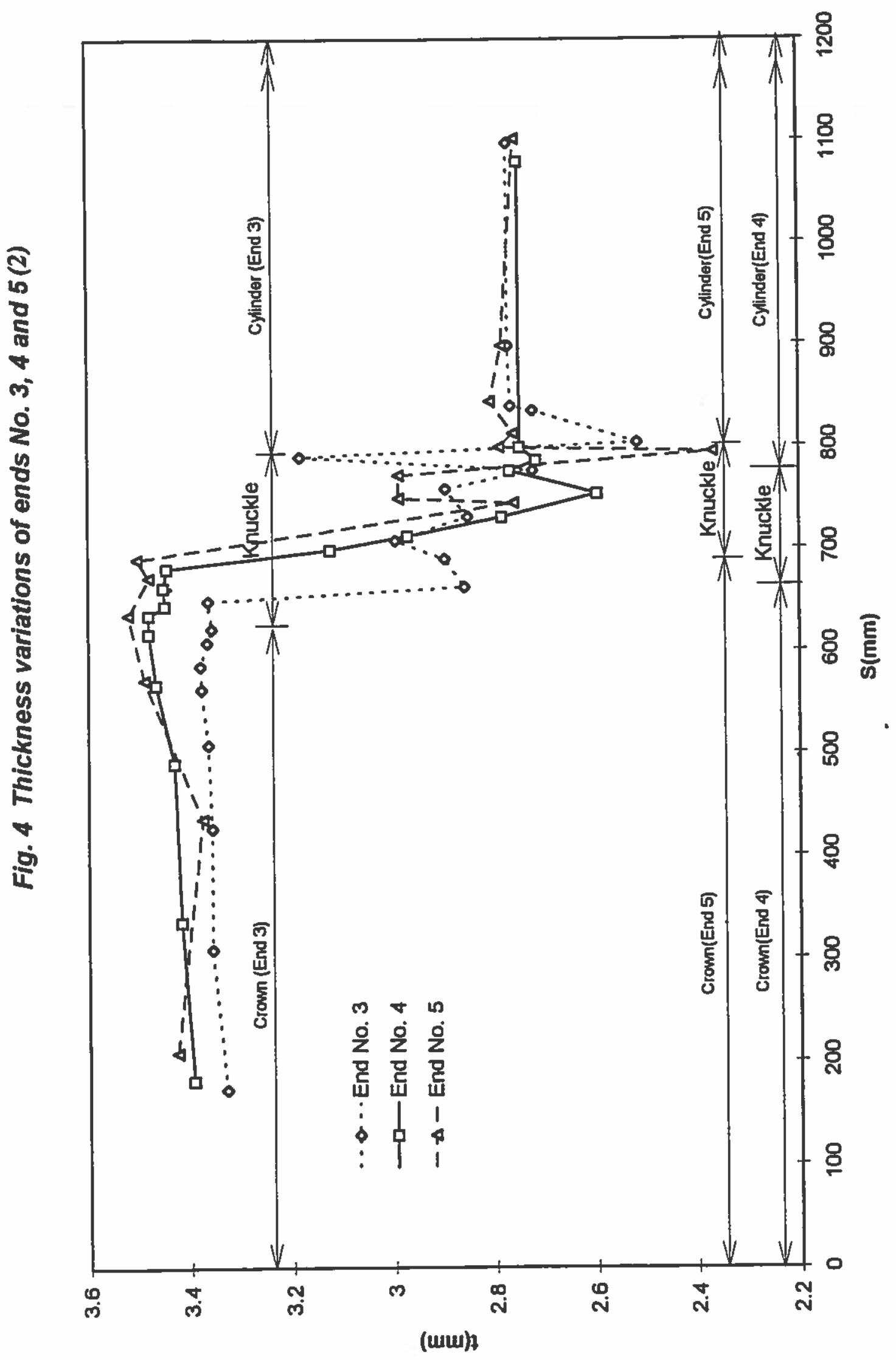


Tafreshi, A. \& Thorpe, T. E. Jul 1996 In : Journal of Strain Analysis for Engineering Design. 31, 4, p. 315-324 10 p.

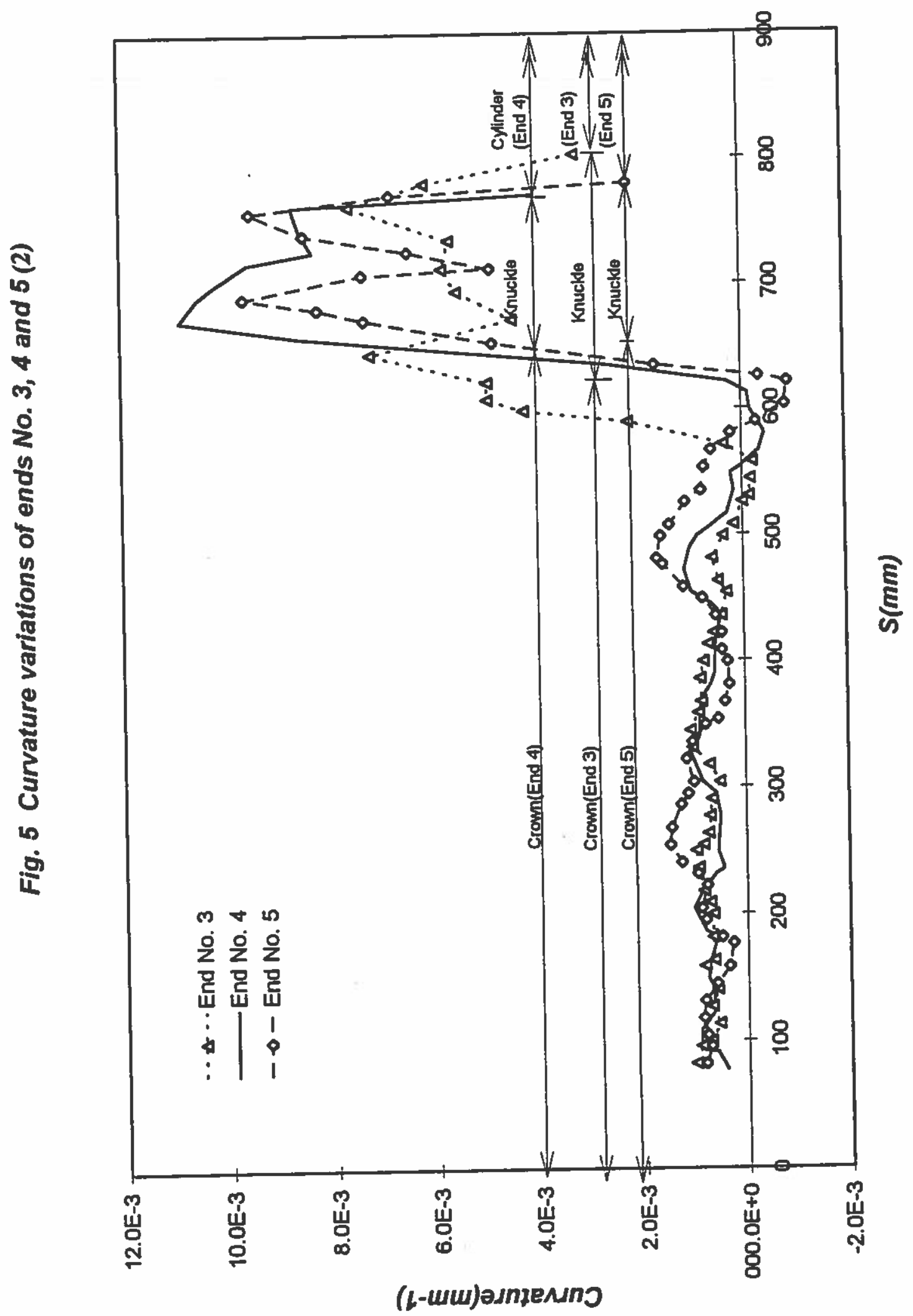


Tafreshi, A. \& Thorpe, T. E. Jul 1996 In : Journal of Strain Analysis for Engineering Design. 31, 4, p. 315-324 10 p.

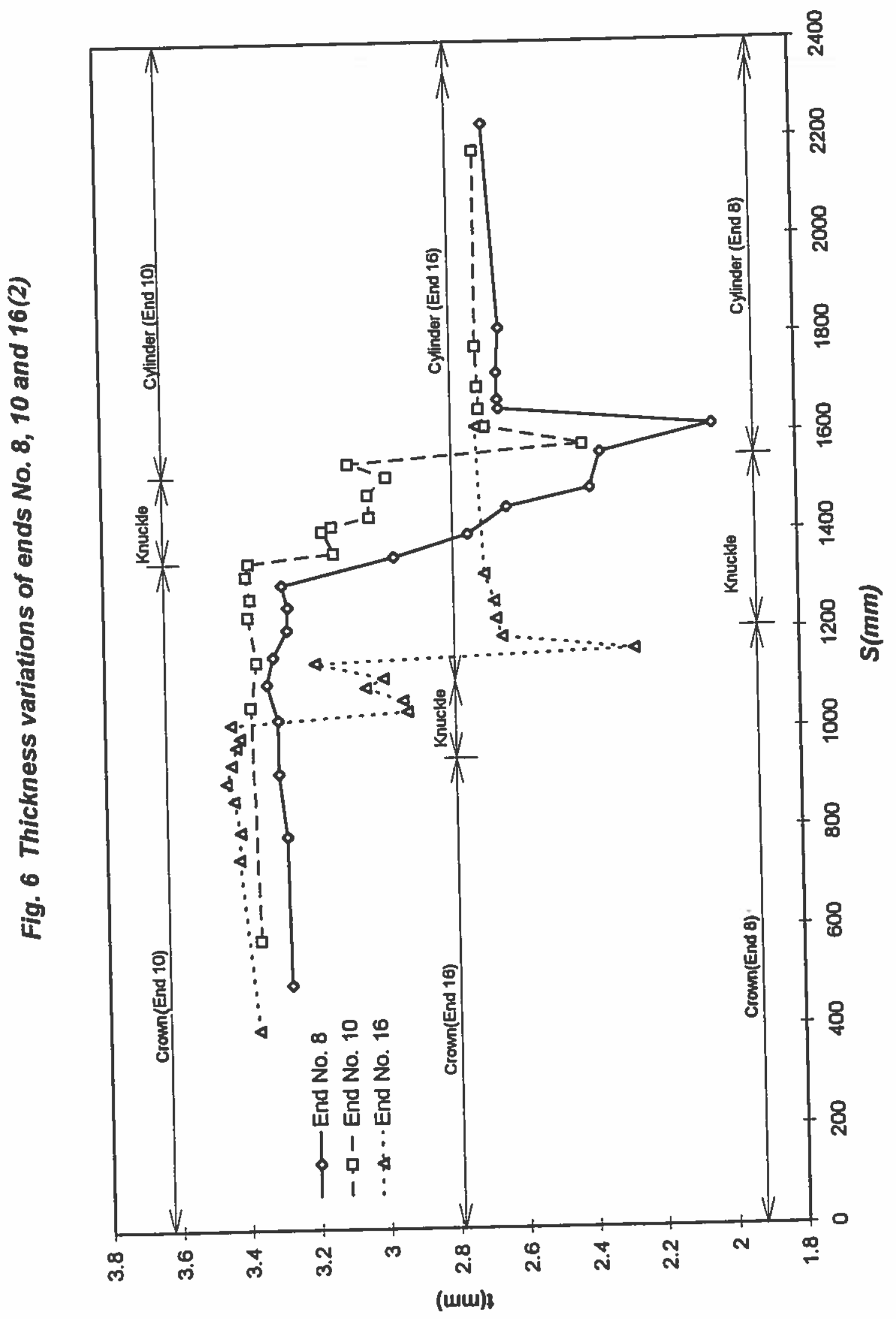


Tafreshi, A. \& Thorpe, T. E. Jul 1996 In : Journal of Strain Analysis for Engineering Design. 31, 4, p. 315-324 10 p.

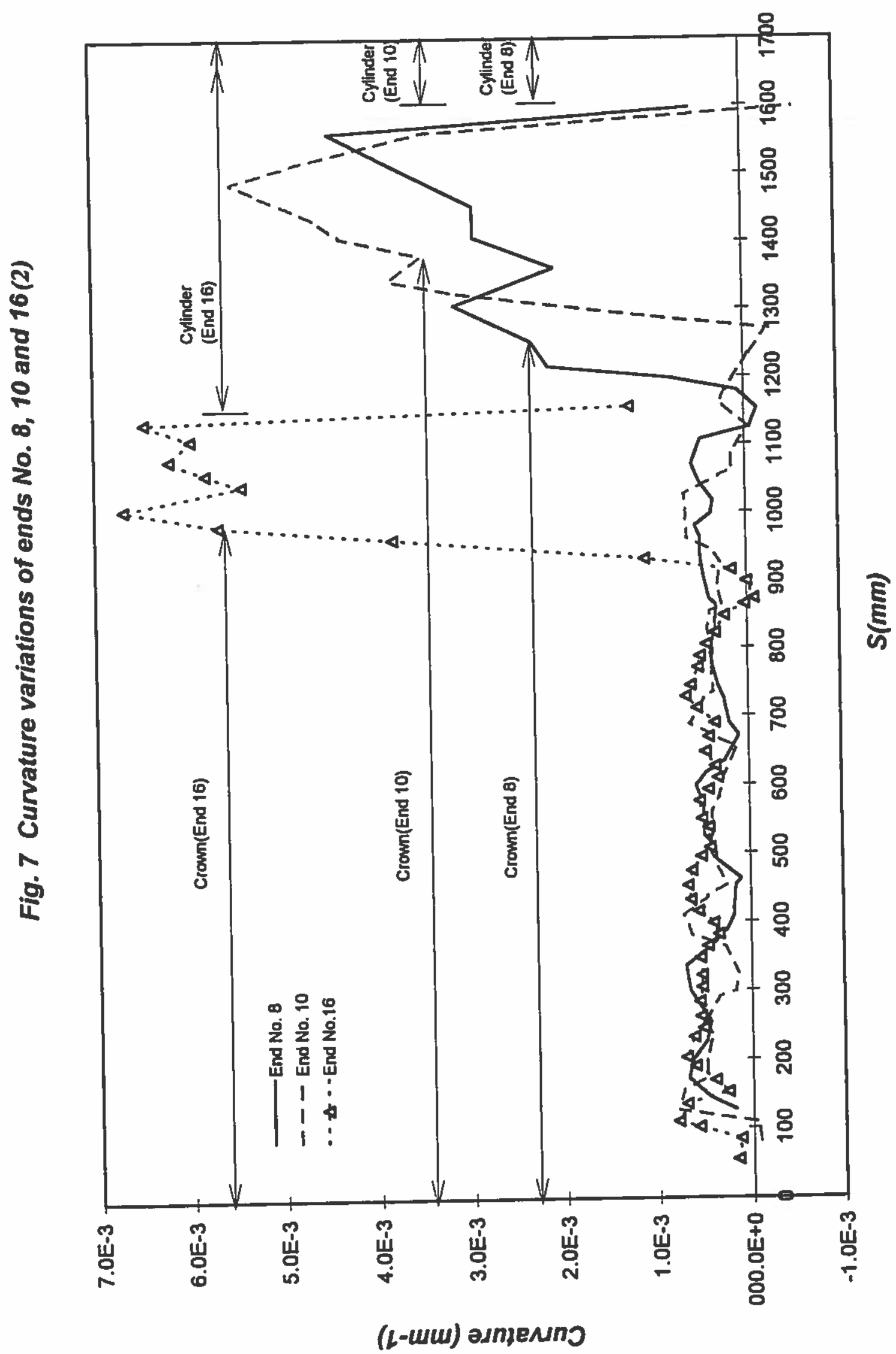


Tafreshi, A. \& Thorpe, T. E. Jul 1996 In : Journal of Strain Analysis for Engineering Design. 31, 4, p. $315-32410$ p.

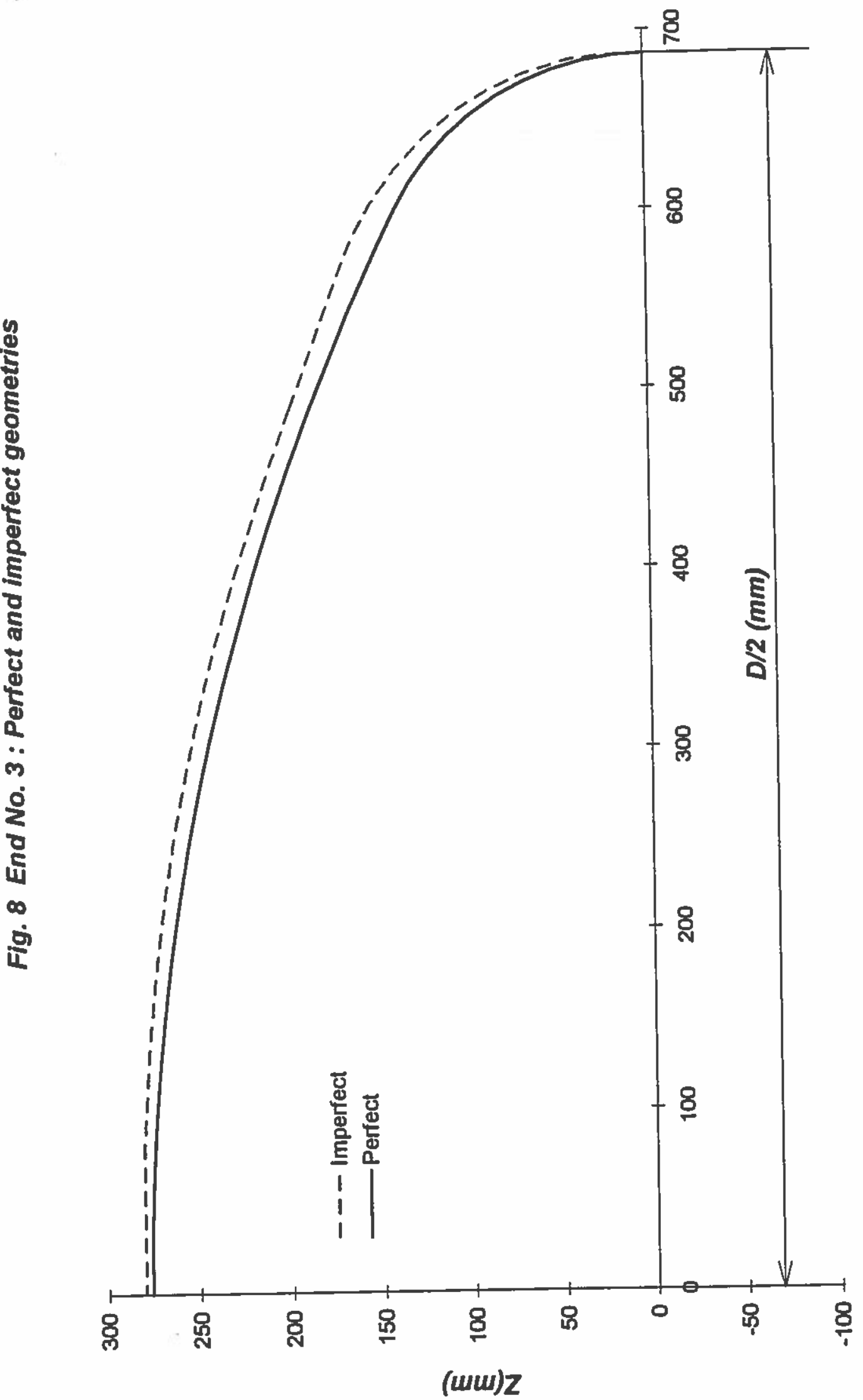


Tafreshi, A. \& Thorpe, T. E. Jul 1996 In : Journal of Strain Analysis for Engineering Design. 31, 4, p. 315-324 10 p.

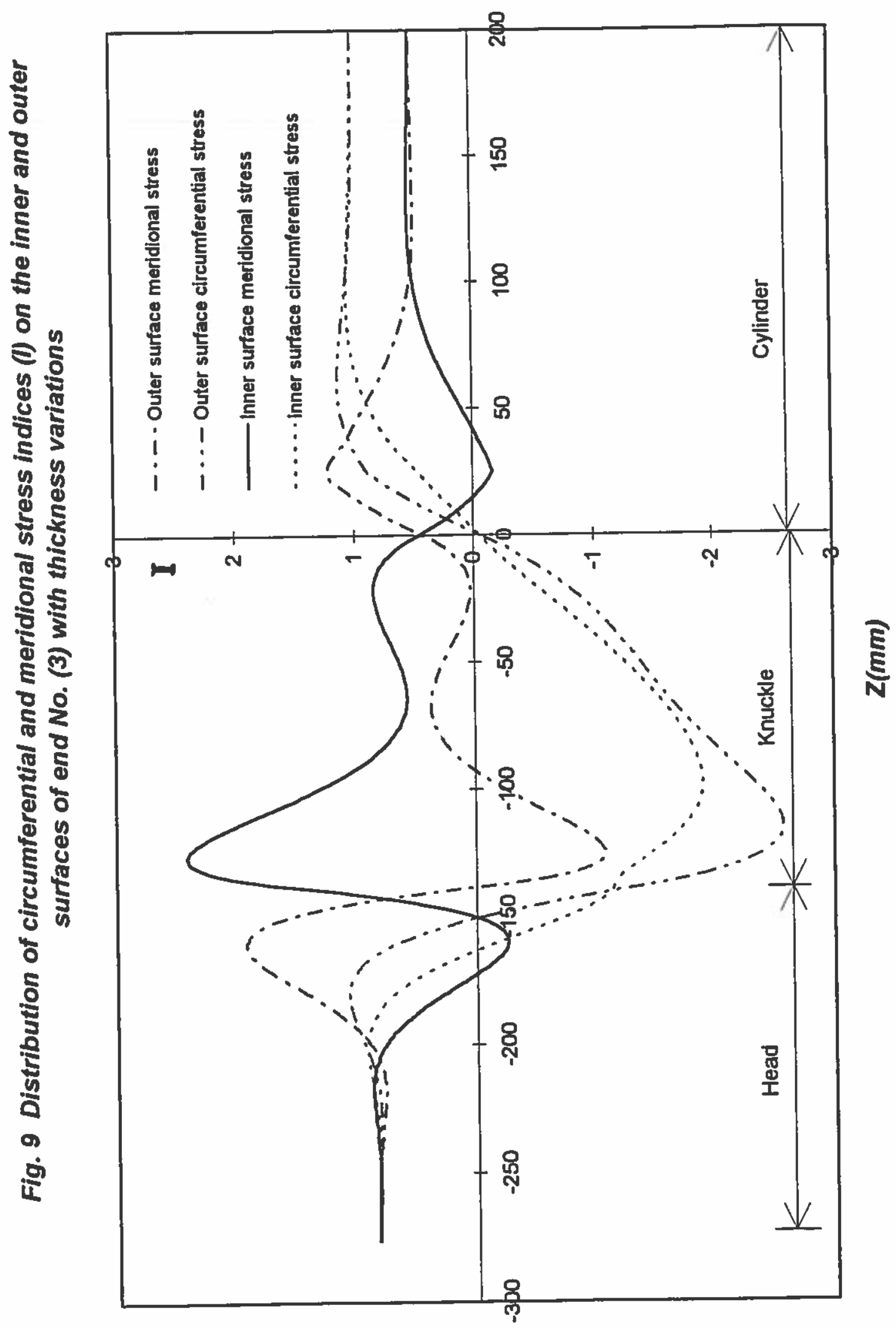




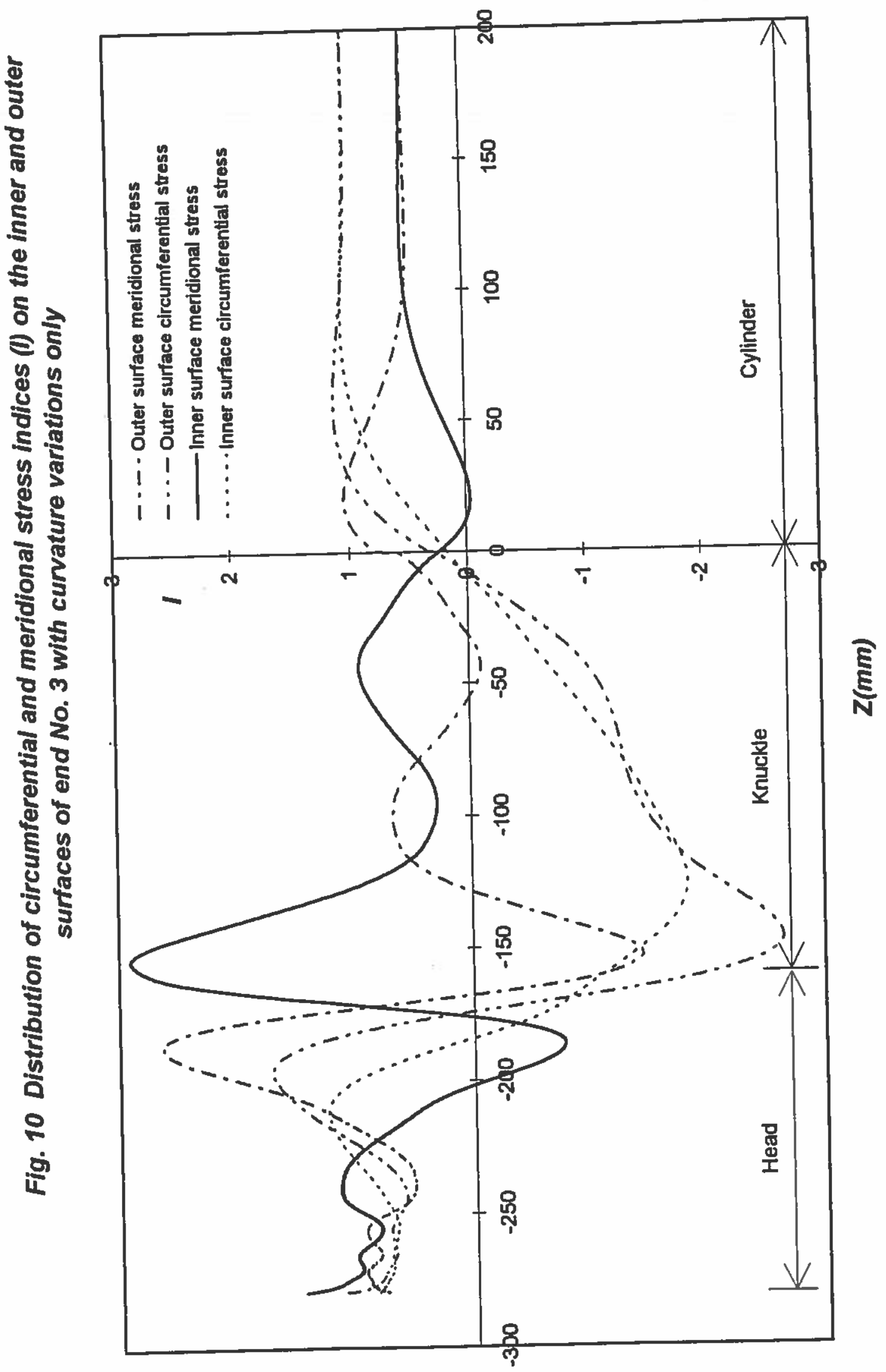


Tafreshi, A. \& Thorpe, T. E. Jul 1996 In : Journal of Strain Analysis for Engineering Design. 31, 4, p. $315-32410$ p.

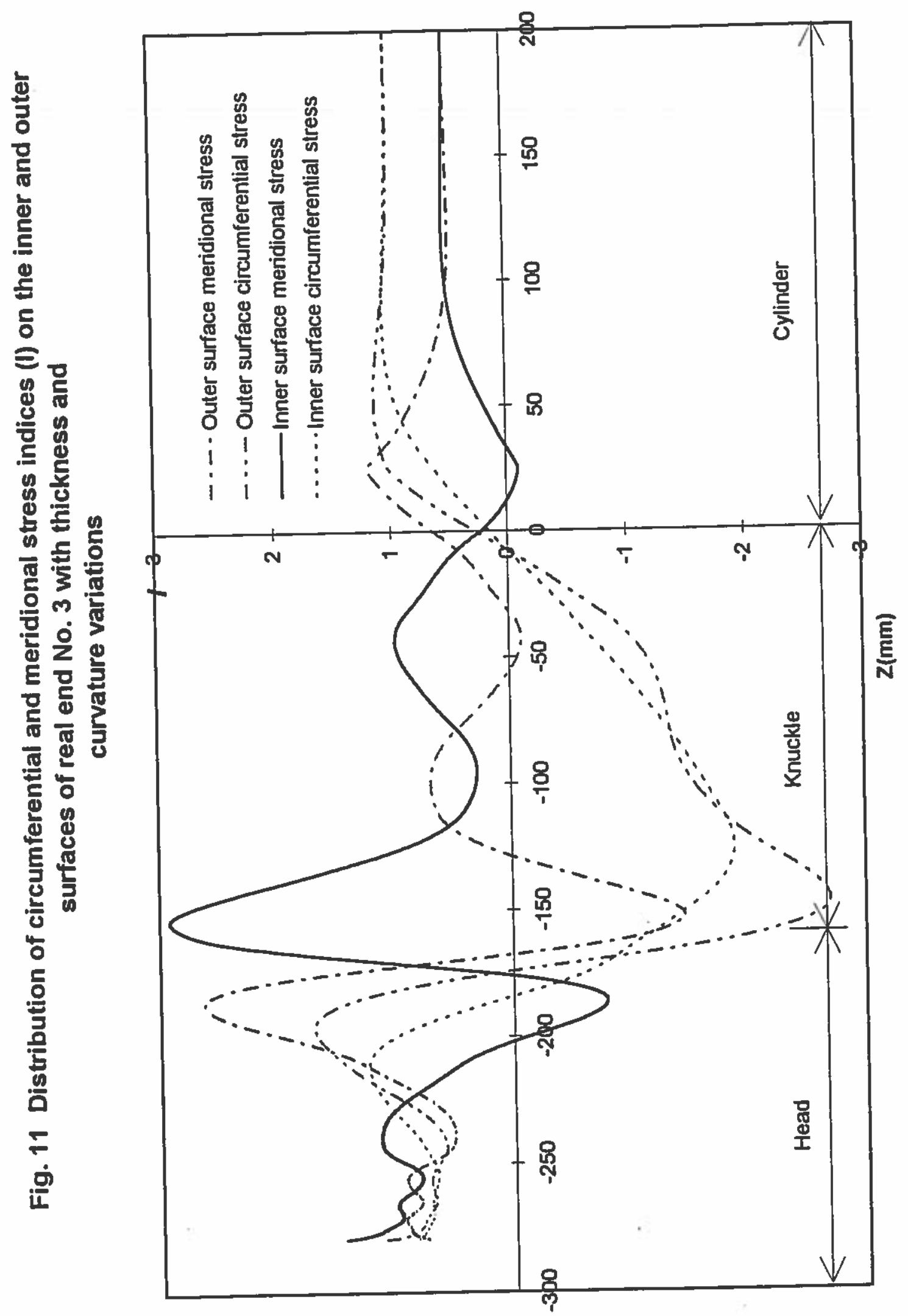


Tafreshi, A. \& Thorpe, T. E. Jul 1996 In : Journal of Strain Analysis for Engineering Design. 31, 4, p. 315-324 10 p.

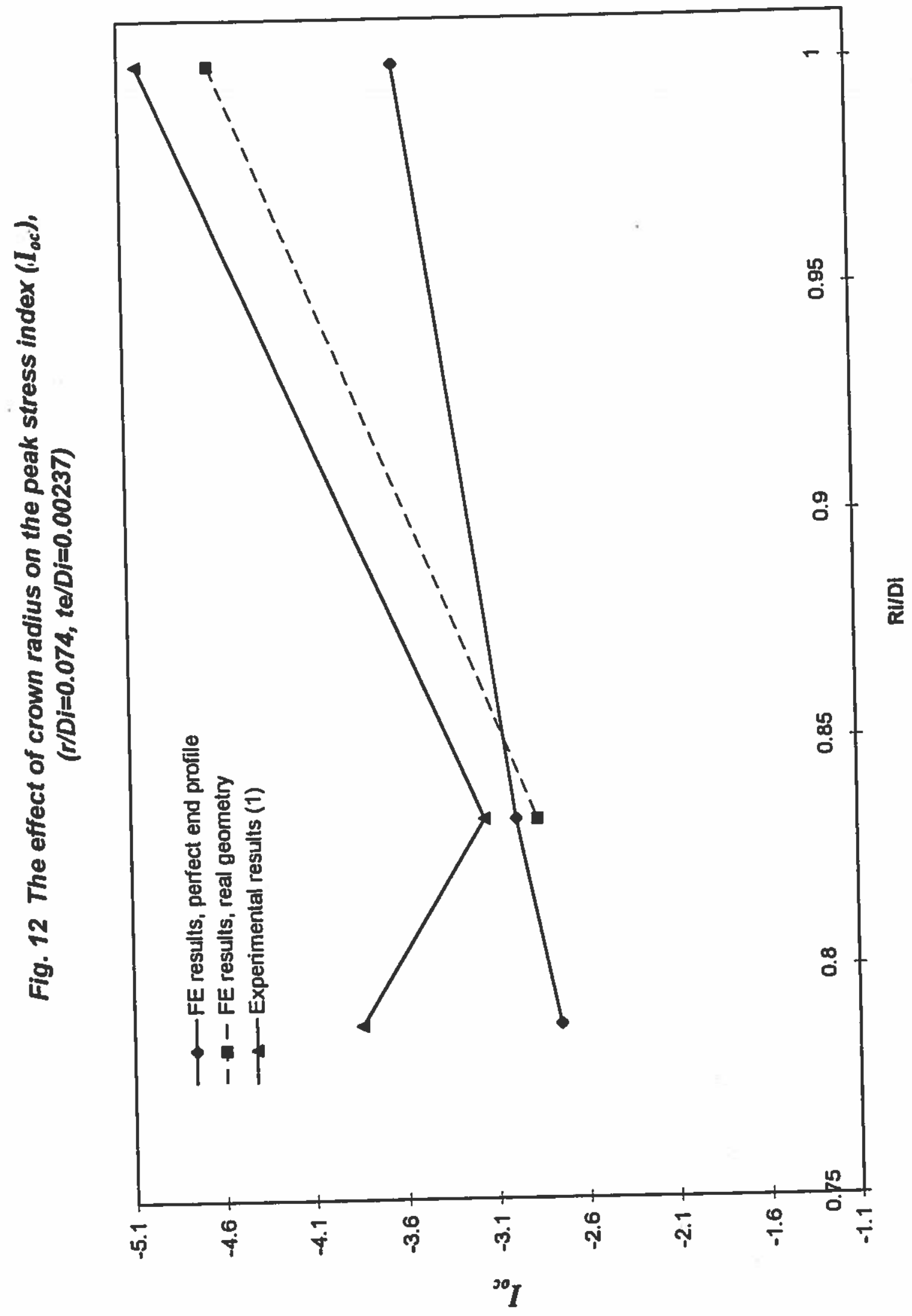


Tafreshi, A. \& Thorpe, T. E. Jul 1996 In : Journal of Strain Analysis for Engineering Design. 31, 4, p. $315-32410$ p.

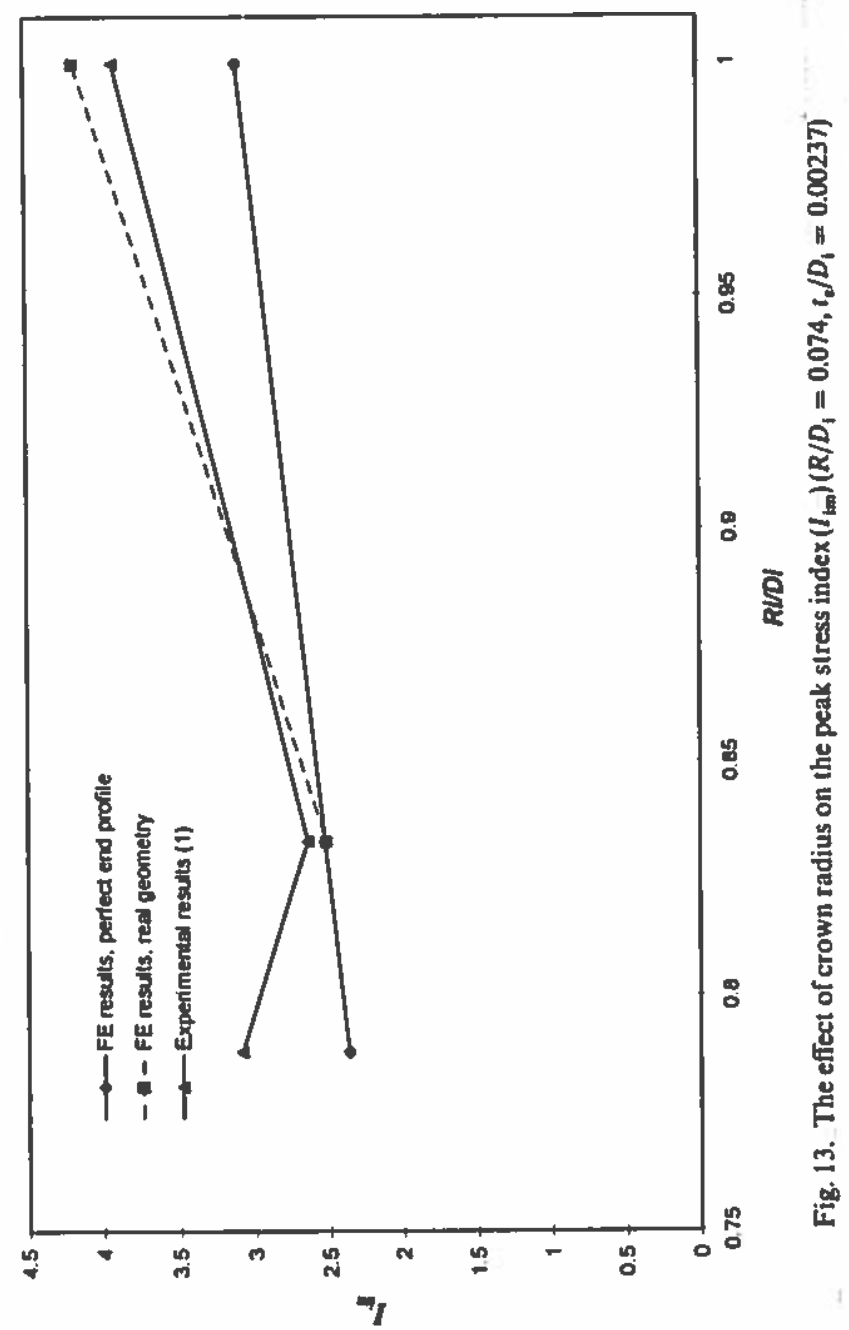

